\title{
China's Situation of Paid Annual Leave and Its Influence on Tourism Consumer Behaviors: A Research Based on a National Survey
}

\author{
Yujing Zhang1, Bin Liao² \\ ${ }^{1}$ Graduate School of Chinese Academy of Social Sciences, Beijing, China \\ ${ }^{2}$ Collaborative Innovation Center of e-Tourism, Tourism College of Beijing Union University, Beijing, China \\ Email:253530163@qq.com, bnuliaobin@126.com
}

How to cite this paper: Zhang, Y. J., \& Liao, B. (2017). China's Situation of Paid Annual Leave and Its Influence on Tourism Consumer Behaviors: A Research Based on a National Survey. Chinese Studies, 6, 234-248.

https://doi.org/10.4236/chnstd.2017.64022

Received: September 27, 2017

Accepted: November 7, 2017

Published: November 10, 2017

Copyright $\odot 2017$ by authors and Scientific Research Publishing Inc. This work is licensed under the Creative Commons Attribution International License (CC BY 4.0). http://creativecommons.org/licenses/by/4.0/

\begin{abstract}
This paper investigates implementation of Workers Paid Annual Leave Regulations, and also analyses whether and how this regulation affects tourism consumer behaviors. The author designs questionnaires and administers them to 5884 subjects distributed throughout 7 regions in China to collect primary objective data about the situation of paid vocation and tourists' behaviors. Based on data analysis, this research concludes that the regulation has not been implemented successfully, that people have more paid days off, they have more leisure travel and higher satisfaction with travelling, and that people who work for state-owned enterprises and public institutions enjoy more paid days off than those migrant workers and employees of private enterprises. It is therefore recommended that the Central Government should take three effective measures to promote implementation of paid leave regulations.
\end{abstract}

\section{Keywords}

Workers Paid Annual Leave, Tourist Behaviors, Policy Recommendations

\section{Introduction}

Since October 1 1999, China has been made three 7-day public holidays, May Day holiday (being cancelled in 2007), National Day holiday, and the Spring Festival holiday, collectively called Golden Week Holiday, and then Holiday Tourism appeared crowed with people and with heavy traffic, making lower degree of tourism customer satisfaction. For improving this situation, Workers Paid Annual Leave Regulations was promulgated by the State Council in January 1, 2008. This law entitles workers to enjoy at least five days' off with pay who 
have worked for more than one year, which means that people will have individual time to go to travel.

In the following year, Professor Wang Weihong (Wang, 2009) compares travellers' behaviors after the promulgation of Workers Paid Annual Leave Regulations with those of before. He maintains that people have more individual leisure travel behaviors after the implementation of Annual Leave. Zhu Haiyan (Zhu, 2010) argues that the implementation of paid holiday system makes people travel short distances more frequently. Zhao Yuan (Zhao, 2015) analyzes the influence factors of people's tourism demands in Hohhot, and she concludes that lacking of leaves is the key restrictive factor in leisure travelling for local residents.

While talking about the significance of the Paid Leave to tourism industry, Wang Xingbin (Wang, 2008) believes that to establish a paid annual leave for all employees will stimulate people's leisure demands, change the style of leisure activities thus promote leisure tourism industry growth in real terms. Kong Yinghong and Liao Pei (Kong \& Liao, 2009) assert that Annual Leave makes a significant contribution to promote sound and rapid tourism industry growth, and they make suggestions of how responding to this Leave System for tourism spot, tourist lodging and catering. Zhang Xiaofeng (Zhang, 2015) argues that the holiday system stimulates the demands for self-driving tour and jaunt, and the peak travel pressure is alleviated, but meanwhile, imbalance between supply and demand appears, resulting in security issues in public traffic, tourist lodging and catering. Wang Lijuan (Wang, 2010) maintains that implementation of Workers Paid Annual Leave Regulations is crucial to balance development of tourism industry.

On the other hand, it is found that the Paid Leave System is not implemented completely, which to a large depends on the degree of social and economic development. Firstly, lots of workers are still law-ignorant and lack of consciousness of their Paid Leave entitlement, as shown by Song Rui (Song, 2015), professor majoring in leisure and tourism studies of Tourism Research Centre of Academy of Social Sciences, making a study of China's situation of Annual Leave based on a National survey of 2013 , only $43.8 \%$ of respondents signed a contract with their companies they worked for, with terms of Paid Leave; and only $31.3 \%$ of respondents enjoyed the Annual Leave freely, so enhancing superintendence of implementation of Annual Leave was indispensable. Secondly, because of profit pursuit, some enterprises deprived of their employees' Paid Leave, MengSibao and GengYongzhi (Meng \& Geng, 2015) argue that enterprises will shrinks their production in response to their rising business cost which is generated by providing paid days off for employees, which will lead to unemployment. Finally, incomplete of legal system about workers' paid leave results in its inadequate implementation. Liu Jing (Liu, 2013) believes that it is necessary that schedule and guarantee strategies be made to implement Workers Paid Annual Leave Regulations successfully.

\section{Method}

This paper uses a questionnaire (as shown in Appendix 1) approach to test the implementation of Paid Vocation and explores the correlation between the days 
of annual leave employees enjoyed and their leisure travel behaviors. 20 questions are listed on the questionnaire about people's demographic information, attitude to leisure travel and tourism behaviors.

This survey was administered to 5884 subjects, distributed throughout 7 regions in China, covering 14 prefecture-level cities including urban districts, small towns and villages (as shown in Appendix 2), using online and street intercept surveys and door-to-door interviews. Because this paper investigates the issues about Paid Annual Leave, so finally, 3122 employees who have a full-time job are selected, and other 2762 respondents being not employees, such as retiree, students, housewives and so on, are exclusive. The 3122 employees are divided into 6 groups according to their enjoying different working days for annual leave, with details as shown in Table 1.

Moreover, this research compares leisure travel attitudes and activities of respondents between different groups and then tests the effect of the Annual Leave on people's leisure travel behaviors.

\section{Findings}

\subsection{Leisure Consciousness of Respondents}

On the whole, it is considered that people who enjoy more working days for annual leave are more agree with the ideas that leisure travel is indispensable to happiness, that leisure is a basic right of citizens, that it is worthy of spending money or time on leisure and that I prefer travelling to other leisure activities, as shown in Figure 1 to Figure 3. However, it is important to note that people who enjoy 1 to 2 days for annual leave are most negative to leisure, but who enjoy 3 5 working days for annual leave are most positive. This means that 5-day annual leave is the crucial factor stimulating people's leisure demands, with too short being a restrictive one and too long being not significant, also as shown in Figure 1 to Figure 3.

Table 1. Basic information of respondents among 6 groups.

\begin{tabular}{lccccccc}
\hline & No leave & $\begin{array}{c}1 \text { day or } \\
2 \text { days }\end{array}$ & $\begin{array}{c}3-5 \\
\text { days }\end{array}$ & $\begin{array}{c}6-10 \\
\text { days }\end{array}$ & $\begin{array}{c}11-15 \\
\text { days }\end{array}$ & $\begin{array}{c}\text { More than } \\
15 \text { days }\end{array}$ & $\begin{array}{c}\text { Amount } \\
\text { to }\end{array}$ \\
\hline $\begin{array}{l}\text { Civil servant and } \\
\text { public institution staff } \\
\begin{array}{l}\text { Staff of State-owned } \\
\text { enterprise }\end{array}\end{array}$ & 92 & 15 & 80 & 147 & 81 & 49 & 464 \\
$\begin{array}{l}\text { Employee in foreign } \\
\text { companies }\end{array}$ & 33 & 11 & 58 & 90 & 41 & 14 & 551 \\
$\begin{array}{l}\text { Employee of private } \\
\text { enterprise }\end{array}$ & 1068 & 44 & 263 & 274 & 65 & 43 & 1757 \\
$\begin{array}{l}\text { Migrant worker } \\
\text { Amount }\end{array}$ & 90 & 1 & 2 & 6 & 1 & 3 & 103 \\
Amount & 1375 & 100 & 494 & 738 & 275 & 140 & 3122 \\
\hline
\end{tabular}

a. first line, annual leave days' category; a. first column, occupation category; a. numbers, number of subjects. 


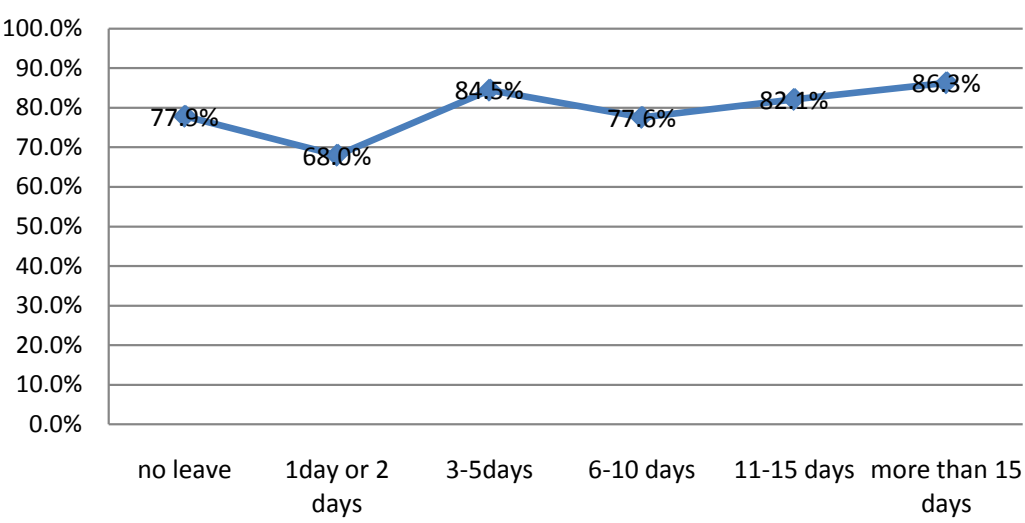

Figure 1. Agree or strongly agree with the idea that leisure travel is indispensable to happiness.

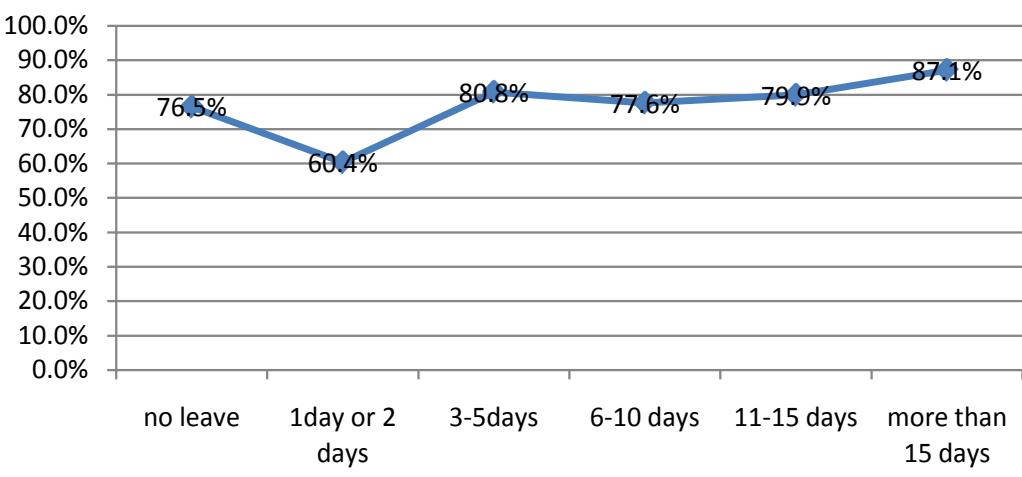

Figure 2. Agree or strongly agree with the idea that leisure is a basic right of citizens.

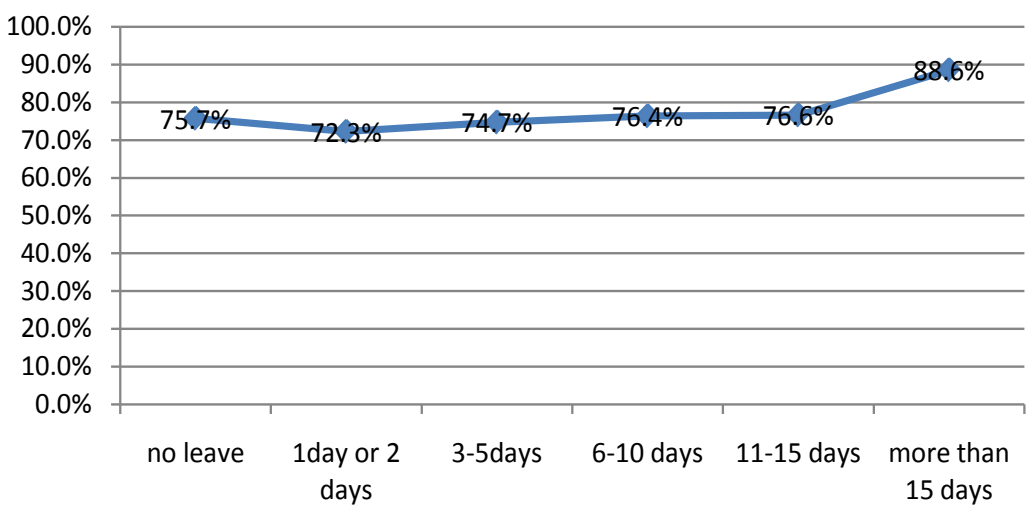

Figure 3. Agree or strongly agree with the idea that it is worthy of spending money or time on leisure.

On the other hand, respondents with no annual leave have more positive attitude to those leisure ideas than ones who only enjoy 1 day or 2 days' leave, the most likely reason for which is that education is another factor influencing ideas of people for leisure. For Figure 4 reveals that respondents with no annual leave have the lowest education, but from Figures 2-5, they are more positive to leisure than those with 1 or 2 days' annual leave. 


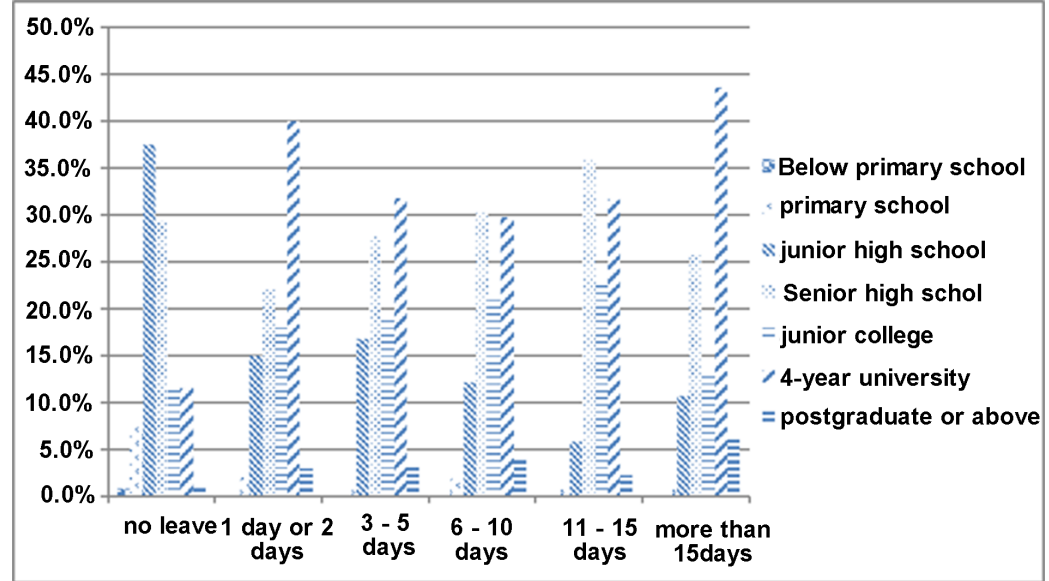

Figure 4. Education of respondents in different groups.

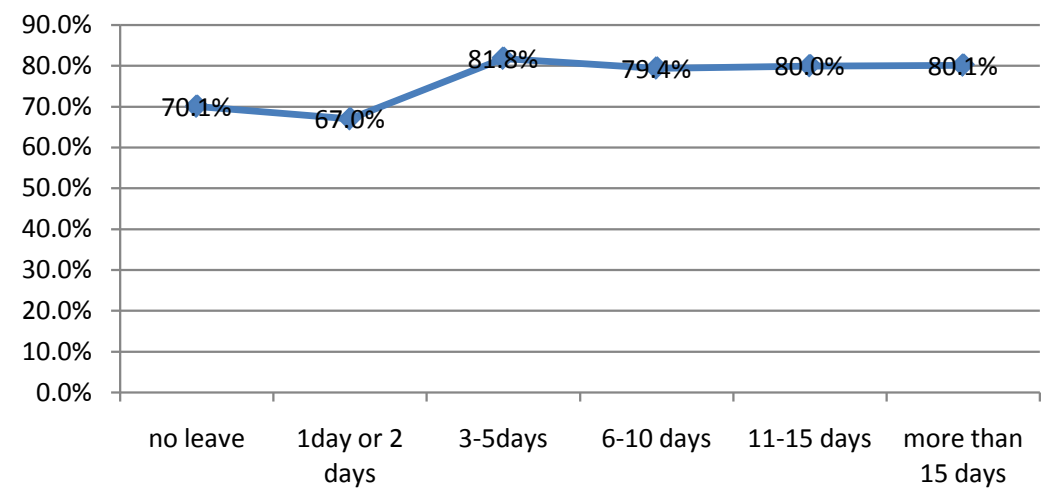

Figure 5. Agree or strongly agree with the idea that I prefer travelling to other leisure activities.

Generally speaking, most of the uneducated or less-educated people are migrant workers or employees without good social position or better salary, they lack of the consciousness and ability to pursuit their own enterprise, so they have more attitude to leisure, but in real life, their Paid Leave entertainment is deprived.

\subsection{Implementation of Workers Paid Annual Leave Regulations}

According to this survey, Annual Paid Leave has not been implemented successfully. High up to $44 \%$ of employees have never enjoyed any single day's annual leave, and this percentage does not include workers who do not enjoy enough days off entitled to them by the Annual Leave system, as shown in table 1. Moreover, according to Figure 6, overwhelming majority of employees are educated unsuccessfully about Workers Paid Annual Leave Regulations, with only $12.6 \%$ of them being familiar with the regulations, $39.7 \%$ of them knowing it a little and $47.0 \%$ of respondents never heard the policy Workers Paid Annual Leave Regulation.

Also, Figure 7 reveals that people' understanding of Workers Paid Annual Leave Regulation is proportional to their enjoying the working days for annual 


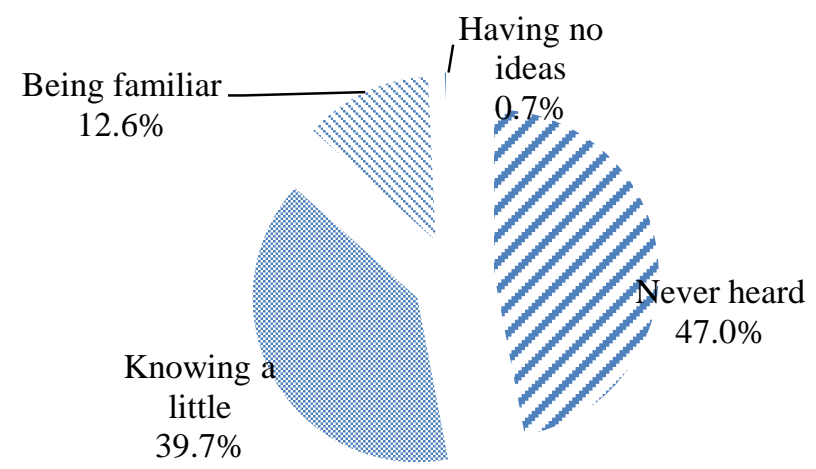

Figure 6. People's understanding of Workers Paid Annual Leave Regulations.

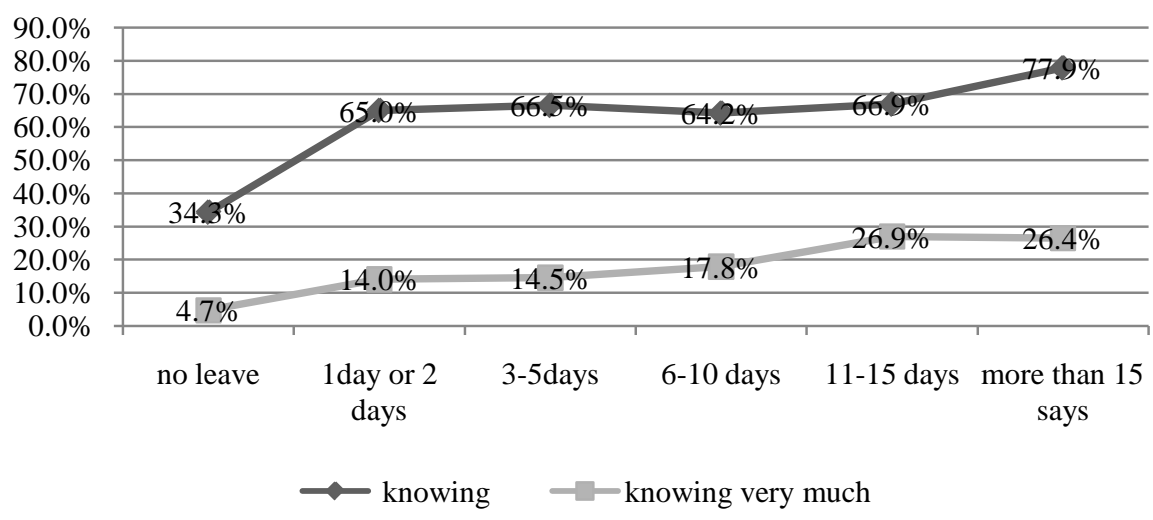

Figure 7. Rates of knowing about Workers Paid Annual Leave Regulations.

leave: the more days, the better understanding of this law. High up to $77.9 \%$ of respondents with more than 15-day annual leave understand Workers Paid Annual Leave Regulation, including knowing a little and being quite familiar with, which is 1.27 times larger than that of people not enjoying any leave day, and approximately 1.2 times as large as that of people with 1 to 2 days, 3 to 5 day, 6 to 10 days, and $11-15$ days.

Furthermore, the correlation is significant among the employees who are intimately familiar with this policy. $26.4 \%$ of the respondents who enjoys more than 15 annual leave days are familiar with Workers Paid Annual Leave Regulation, and the corresponding percentage of persons with 11 - 15 annual leave days is $26.9 \%$, while only $4.7 \%$ of respondents without annual leave are quite familiar with it, and the former is 4.6 times larger than the latter.

\subsection{Correlation between Domestic Leisure Travel Times of Employees and Their Annual Leave Days}

It is obvious that domestic leisure travel times of employees are proportional to their receiving days off for paid vocation: the more days off, the more travel times, as showed in Figure 8. Respondents having no any single day off for paid annual leave have an average of 1.2 travel times for leisure, compared to ones with 1 - 2 days' paid annual leave having 1.8 travel times on the average, with 3 - 5 


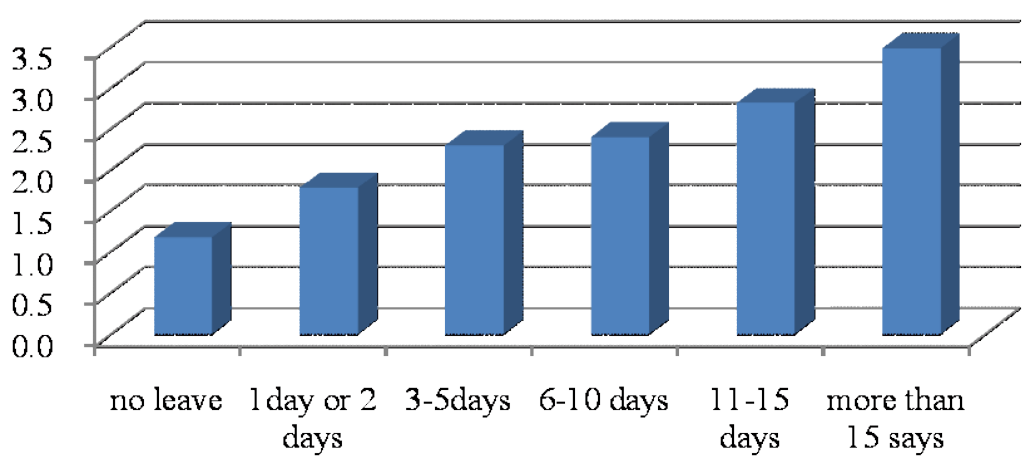

Figure 8. Domestic leisure travel times of employees.

days off 2.3 travel times, with 6 - 10 days off 2.4 travel times, with $11-15$ days off 2.8 travel times, and with more than 15 days off 3.5 travel times.

\subsection{Correlation between Employees' Domestic Leisure Travel Days and Annual Leave Days}

Total domestic leisure travel days of employees are proportional to their enjoying days off with pay: the larger the number of paid days off, the more travel days. Figure 9 shows that the average travel days of per respondents having no annual leave are 3.7, yet people with 1 to 2 days' leave have 5.3 travel days on the average, people with 3 - 5 days' leave 6.5, people with 6 - 10 days' leave 7.1, people with 11 - 15 days' leave 8.4, and people with more than 15 days' leave 11.1.

\subsection{Leisure and Leisure Travel Expenditure}

According to this survey, it is obvious that increase of varying degrees of leisure and leisure travel expenditure could be seen in divided groups of employees enjoying different days off for paid annual leave. On the whole, people have more with-pay days off, their leisure expenditures increase more sharply, and respondents enjoying more than 15 paid days off experience the highest increase in leisure consumption, as Figure 10 is shown.

From Figure 11, it is believed that people expend 6775.2 Yuan on leisure activities on average and 4491.4 Yuan on leisure travelling, namely, $66.3 \%$ of the leisure expenditure is for travelling. By and large, the more days off with pay, the larger the proportion of leisure travelling costing in all leisure expenditure. Respondents with more than 15 days off expend most, 11,334.8 Yuan on travelling and 16,078.5 Yuan on leisure, which separately is 4.4 times and 3.8 times larger than that of people having no annual leave. While employees having 11 - 15 days off have the largest proportion (73.6\%) of leisure travelling cost in leisure expenditure, which is 1.5 times as large as that (48.9\%) people with 1 to 2 days off have.

\subsection{Degree of Satisfaction with Leisure Travelling in Divided Employees with Different Annual Leave}

From Figure 12, we can see that Annual Leave can make people more satisfaction with their leisure travelling. $71.8 \%$ of respondents having annual leave are 


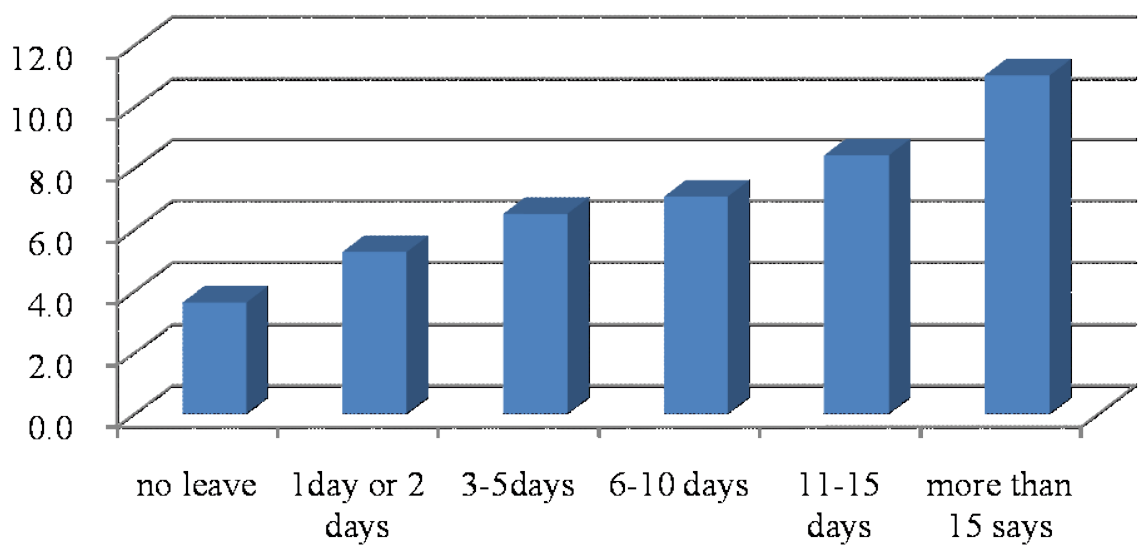

Figure 9. Total domestic leisure travel days on average.

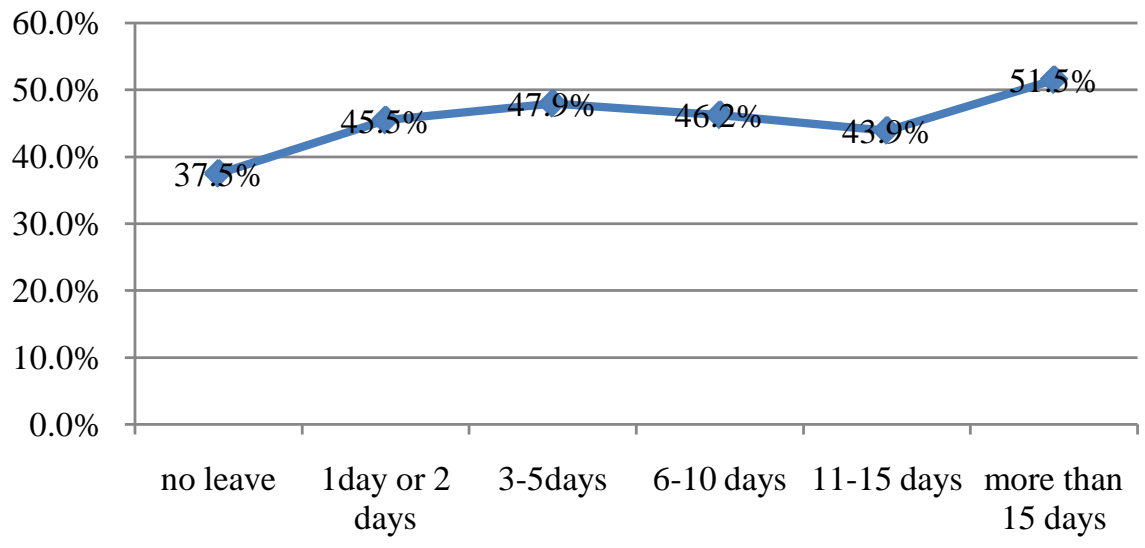

Figure 10. Increase in leisure expenditure.

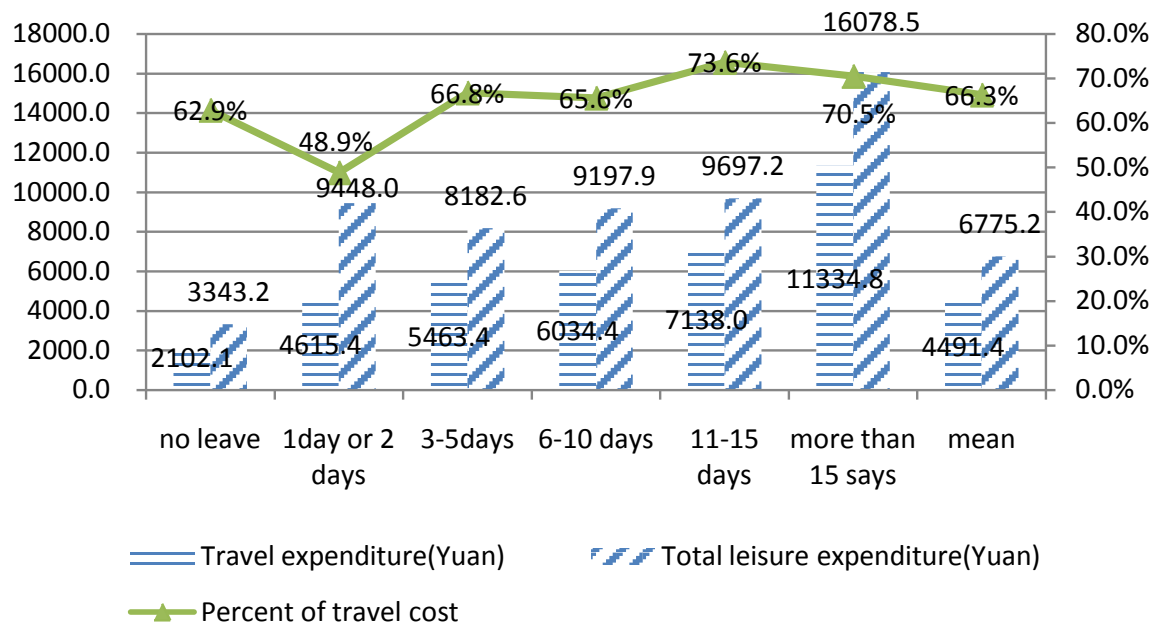

Figure 11. Leisure and leisure travel expenditure.

satisfied with their leisure travelling, which is $18.9 \%$ higher than that of people with no leave. The largest proportion of respondents with higher degree of satisfaction is $75.5 \%$ and these people enjoy more than 15 paid days off a year, while the minimum one is $52.9 \%$, with people does not have paid annual leave. 


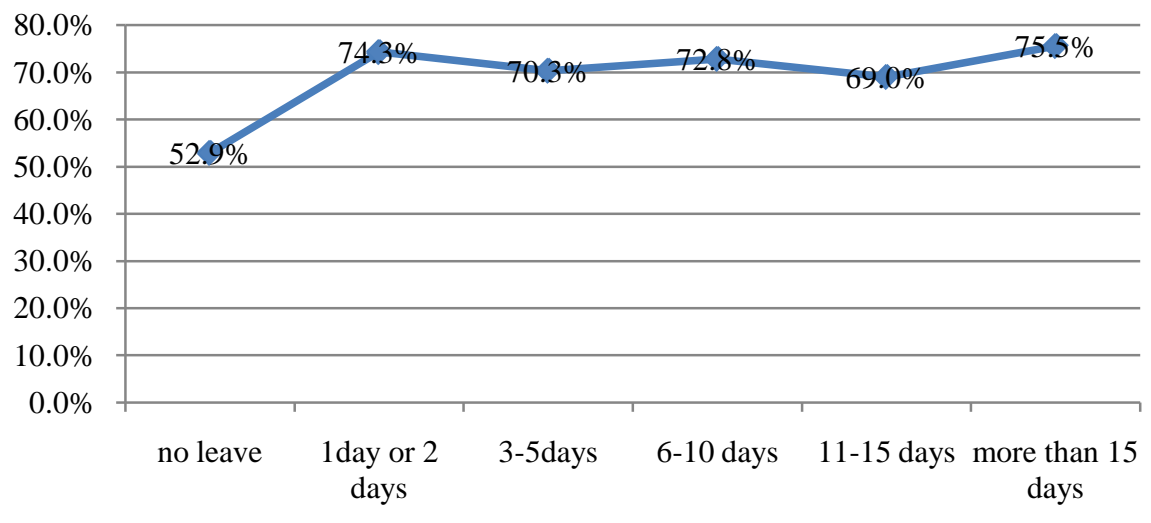

Figure 12. Degree of satisfaction with leisure travelling.

\subsection{The Occupational Distribution of Employees Who Have More Paid Days off}

Figure 13 reveals that among employees without annual leave, the mostly majority are migrant workers and employees of private enterprises, and this proportion is $84.2 \%$, as opposite to which, more than half respondents with more than 10 days' leave are staff of state-owned enterprises and civil servants and public institution staff. Based upon above analysis, it is obvious that people who work for state-owned enterprises and public institution have more leisure time and higher satisfaction with leisure travelling than those migrant workers and employees of private enterprises.

\section{Conclusion}

Paid Annual Leave has not been implemented successfully, and there are still $44 \%$ of employees not having this entitlement, among people without annual leave, the most majority are migrant workers and employees of private enterprises, and it is meant that this law should be strengthened, supervised, and executed properly.

People have more days off for paid annual leave, they have more leisure travel experiences, and they have higher satisfaction with travelling. The educated employees who enjoy more working days' leave have more leisure travel experience, those people understanding more to Workers Paid Annual Leave Regulation enjoying more days for annual leave and also enjoy more travel time, and people enjoying more paid annual leaves have a higher satisfaction to their leisure travel activities.

People who work for state-owned enterprises and public institutions have more leisure time and higher satisfaction with leisure travel than those migrant workers and employees of private enterprises.

So, to improve the holiday benefits of migrant workers and private enterprise employees becomes important, and the government, the enterprises and employees should cooperate.

The Central Government should take effective measures to promote the implementation of Workers Paid Annual Leave Regulations. Firstly, to those who 


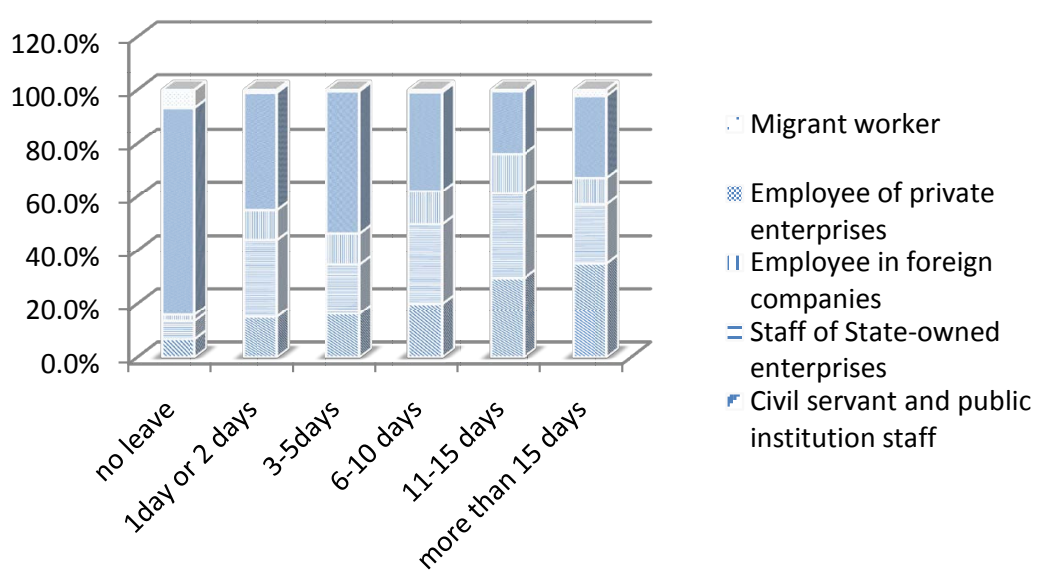

Figure 13. Occupational distribution in divided groups.

work for private enterprises and those who are migrant workers, the Central Government should improve their working environment and provide them more tourism services at a lower price. Meanwhile, the Central Government should supervise and urge private enterprises to implement the Paid Annual Leave System adequately. Secondly, the Central Government should take more measures to broadcast Workers Paid Annual Leave Regulation and help employees enhance their consciousness of annual leave rights. Thirdly, the Central Government should build thorough system of regulations to punish offenders for not providing employees with paid leave of working days.

The private enterprises should strengthen their own sense of social responsibility. Corporate social responsibility has a positive relationship with a company's competitiveness, and a company with high social responsibility can attract more human and financial capital. Taking care of their staff and providing them sufficient Paid Leave are the most important measures reflecting a company's social responsibility.

The migrant workers and private enterprise employees themselves should take self-education and self-train to enhance their own consciousness of Paid Leave entitlement and take up some legal measures to protect their own rights and interests from private enterprise's exploitation.

\section{Implications}

This research reveals the relationship between Paid Annual Leave and tourist behavior, which is significant in social practice and academic research. In social practice aspect, the findings can help central government and tourist make a better choice when involved in holiday tourism and travel. Central government can take relative measures to improve the implementation of Workers Paid Annual Leave Regulations according to this research, and can strengthen the supervision on enterprises' Paid Leave provision for their staffs. People can understand their own entitlement about Paid Leave and protect their own interesting, and also can make their own travel during Paid Leave, obtaining better tourism 
experiences. In academic research aspect, this study reveals the regulations behind the Paid Leave and tourist behavior, making supplement for the research of Holiday System and tourism.

\section{Fund}

This research was supported by grants from "New Start" Academic Research Projects of Beijing Union University (Sk10201607).

\section{Acknowledgements}

The data analyzed in this study was provided by China National Tourism Administration.

\section{References}

Kong, Y. H., \& Liao, P. (2009). On Impacts of the Paid Annual Leave on Tourism. Coastal Enterprises and Science \& the Technology, 12, 92-95.

Liu, J. (2013). A Schedule and Guarantee Strategies Being Necessary for Implementing Paid Annual Leave System. Workers' Daily, 5, 42-49.

Meng, S. B., \& Geng, Y. Z. (2015). The Dilemma of Implementation of Paid Annual Leave System-From Two-Sector Model Perspective. Northern Economy, 2, 77-78.

Song, R. (2015). International Experiences and China's Situation of Paid Vacation: A Study Based on a National Survey. Journal of Graduate School of Chinese Academy of Social Sciences, 7, 42-49.

Wang, L. J. (2010). Empirical Analysis of Impacts of the Reform of National Vacation System on Tourism Industry. Statistics and Management, 19, 133-134.

Wang, W. H. (2009). Impacts of the New Vacation Policy on Tourist Behaviours of Chinese Residents and Counter Measures for Tourism. Tourism Science, 23, 62-68.

Wang, X. B. (2008). The Remodelling of Leisure Tourism. Tourism Forum, 8, 90-93.

Zhang, X. F. (2015). Influence of Holiday System on Tourism Industry and Countermeasures How to Take to Response to This System. Statistic and Management, 9, 101-102.

Zhao, Y. (2015). Analysis of Stimulation of Paid Annual Leave to People's Travelling-Based on the Residents in Hohhot. Livelihood Economy, 4, 77-78.

Zhu, H. Y. (2010). How the Adjustment of Holiday System Can Affect the Development of Tourism Industry? Knowledge Economy, 9, 164. 


\section{Appendixes}

Appendix 1. Chinese Travel Leisure Lives Questionnaire

Dear Ladies/Gentlemen,

May we ask you a few questions about your travel leisure lives in the last year. There is no need to write your name anywhere in this sheet, and we promise your information is completely confidential.

Thank you for your cooperation.

\section{Section one: Demographic Information}

Please answer the following general questions.

\section{1) Your gender}
A. Male
B. Female
2) Your age
A. 18 - 35
B. $36-44$
C. 46 - 59
D. 60 or more

3) Your Education level
A. Below primary school
B. Primary school
C. Junior high school
D. Senior high school
E. Junior college
F. 4-year university
G. Postgraduate or above

\section{4) Your occupation}
A. Civil servant
B. Public institution staff
C. Staff of State-owned enterprise
D. Employee in foreign companies
E. Employee of private enterprises
F. Self-employed
G. Retired
H. Student
I. Migrant worker
J. Other

5) Please estimate your monthly income in RMB
A. Less than 1000
B. $1000-3000$
C. $3001-5000$
D. $5001-8000$
E. $8001-10,000$ 
F. 20,000 or more

6) The city where you currently live in is

7) How many years do you have working for?

A. Less than 1 year

B. Equal to or more than 1 year but less than 10 years

C. Equal to or more than 10 but less than 20 years

D. Equal to or more than 20 years

\section{Section two: Leisure travel behaviors information in 2014}

\section{8) Your attitude to leisure travel.}

Please indicate in following statements if you $1=$ Strongly disagree, $2=$ Disagree, $3=$ Neither agree nor disagree (Neutral), $4=$ Agree and $5=$ Strongly agree.

Statements

Leisure travel is indispensable to happiness. $\begin{array}{lllllll}1 & 2 & 3 & 4 & 5\end{array}$ $\begin{array}{lllllll}\text { Leisure is a basic right of citizens. } & 1 & 2 & 3 & 4 & 5\end{array}$

$\begin{array}{lllllll}\text { It is worthy of spending money or time on leisure } & 1 & 2 & 3 & 4 & 5\end{array}$

I prefer to accept a less well-paid job in return for leisure time. $\begin{array}{llll}1 & 2 & 3\end{array}$

45

I prefer travelling to other leisure activities. $\begin{array}{lllllll}1 & 2 & 3 & 4 & 5\end{array}$

9) Which kind of leisure activities do you prefer? (Please select one choice).
A. Home
B. Suburban tourism
C. Short-haul travel
D. Long-haul travel

10) How much do you know about Workers Paid Annual Leave Regulations?
A. No
B. A little
C. Normal
D. Much
E. Very much

11) I spend leisure time on travelling I did last year.

A. more... than

B. the same... as

C. less... than

12) I spend money on travelling I did last year.

A. more... than

B. the same... as

C. less... than

13) How many days of Annual Paid Leave did you enjoyed in 2014?

A. None

B. 1 - 2 days 
C. 3 - 5 days

D. 6 - 10 days

E. 11 - 15 days

F. More than 15 days

G. I have no job

14) If you did not enjoy Annual Paid Leave in 2014, and why?

A. My enterprise did not implement it.

B. For my promotion to a higher office.

C. For three times the daily wage.

D. I do not know I have this right.

15) The number of my domestic leisure travel times is in 2014 .

16) The number of my domestic leisure travel days is in 2014.

17) I mostly went to travel for leisure by in 2014.

A. air

B. train/high-speed rail

C. coach

D. driving

18) The total cost of my leisure lives is Yuan (RMB) in 2014, and the number of cost of my travel leisure is Yuan.

19) Generally speaking, your evaluation of your leisure travel lives in 2014 ?
A. Strongly dissatisfaction
B. Dissatisfaction
C. Neutral
D. satisfaction
E. Strongly satisfaction

20) What are your suggestions about how to improve the Annual Paid Leave? 
Appendix 2. The cities, towns and villages where the survey is administered.

\begin{tabular}{|c|c|c|c|}
\hline City, Town and Village & City & Town & Village \\
\hline Zhuji, Shaoxing, Zhejiang & & 145 & 709 \\
\hline Changle, Fuzhou, Fujian & & 79 & 466 \\
\hline Beizhen, Jinzhou, Liaoning & & 106 & 325 \\
\hline Xinji, Shijiazhuang, Hebei & & 106 & 406 \\
\hline Linxiang, Yueyang, Hunan & & 79 & 347 \\
\hline Pengzhou, Chengdu, Sichuan & & 343 & 399 \\
\hline Xingping, Xianyang, Shanxi & & 317 & 273 \\
\hline Beijing & 284 & & \\
\hline Shanghai & 314 & & \\
\hline Guangzhou & 157 & & \\
\hline Shenzhen & 66 & & \\
\hline Foshan & 87 & & \\
\hline Qingdao & 84 & & \\
\hline Hangzhou & 103 & & \\
\hline Suzhou & 76 & & \\
\hline Taiyuan & 66 & & \\
\hline Zhengzhou & 136 & & \\
\hline Xi'an & 132 & & \\
\hline Chengdu & 128 & & \\
\hline Mianyang & 29 & & \\
\hline Shenyang & 121 & & \\
\hline Amount & 1783 & 1175 & 2926 \\
\hline
\end{tabular}

